\title{
'Matan', a New Self-compatible Almond Cultivar with High-quality Kernel and Good Yield
}

\author{
Doron Holland', Irit Bar-Ya'akov, and Kamel Hatib \\ Unit of Deciduous Fruit Tree Sciences, Agricultural Research Organization, \\ Newe-Ya'ar Research Center, P.O. Box 1021, Ramat Yishay 30095, Israel
}

\section{Reuven Birger \\ Valley Farmers Center, P.O. Box 73, Migdal Haemek 23100, Israel}

Additional index words. Prunus amygdalus Batsch, Prunus dulcis [(Miller) D.A. Webb], new Israeli cultivar, self-compatibility

Modern orchards in Israel are based on one old local cultivar, Um ElFahem $(\approx 70 \%)$, and its pollenizers 'Kochav', 'Gilad', 'Shefa', and 'Kochba'. All of them are locally bred cultivars. Because of their inconsistent flowering periods that vary with year and the constantly changing climatic conditions, two pollinating cultivars are customarily used in current orchards to cover the early and late flowering stages of 'Um ElFahem'. Thus, at present, about one-third of the orchard area is devoted to pollenizers and not all of them of satisfactory quality. All of those pollenizers are highly adapted to the Israeli climate and yield sweet kernels that are favored by the Israeli costumer. Over the last decades, 40 commercial and newly bred cultivars were introduced from France, Spain, and the United States. None of them performed well under the growing conditions of Israel. Among the tested cultivars, the selfcompatible 'Lauranne' and 'Guara' were found to be highly productive but their nut quality could not compete with that of the Israeli cultivars (Birger, 2000; Holland et al., 2003, 2006). In Israel, 'Um ElFahem' and its pollenizers flower during the rainy season. Cloudy, cold, and rainy hours limit the efficiency of honeybees' activity and of pollen germination, and thus pollination is negatively affected. The reliance of the almond growers solely on one cultivar on one hand, and on pollinating vectors, namely honeybees, on the other hand, are two major disadvantages that affect the production. These drawbacks raised the need for new good-quality self-pollinating Israeli cultivars that contain the dominant $S f$ allele (López

Received for publication 30 Dec. 2015. Accepted for publication $2 \mathrm{Feb} .2016$

We thank Baruch Bar-Tel and David Lahav for operating the registration of the cultivar in Israel and in various places in the world and the Chief Scientist of the Israeli Ministry of Agriculture and Rural Development and the Plants Production and Marketing Board for financing the almond breeding program.

${ }^{1}$ Corresponding author. E-mail: vhhollan@agri. gov.il. et al., 2001). Here, we describe the characteristics of 'Matan', a newly bred cultivar, with self-compatibility producing high yield, large size, and sweet kernels.

\section{Origin}

'Matan' was bred in the Newe Ya'ar Research Center, located in the Yizre'el Valley, Israel. It is the result of a long-term almond breeding program held in Newe Ya'ar, aimed to develop new cultivars that excel at high production of good-quality nuts, concentrating on self-fruitful cultivars.

'Matan' \{Prunus dulcis [(Miller) D.A. Webb] $\}$ is a selection from seedlings originating from a cross between 'Lauranne' and 'Um ElFahem'. The female parent 'Lauranne' is a French self-pollinating cultivar (Kester, 1995), and the pollen donor is ' $U m$ ElFahem', the Israeli main commercial cultivar (Barak and Adawi, 1971). 'Um ElFahem' is of local origin and is listed in the Israel Plant Gene Bank (http://igb.agri.gov.il/ main/index.pl?page=22). Polymerase chain reaction (PCR) technology with specific primers for the $S f$ allele was used to detect the presence of the desired $S f$ allele in the crossbred progenies (Holland et al., 2006). Hybrid seedlings, determined as containing the $S f$ allele by PCR, were planted in Newe Ya'ar almond orchard in 2003. Seedling no. 4/9 was selected in 2006 and named as 'Matan' in 2008. Budwood of 4/9 was grafted on GF-677 rootstock, and the resulting trees were planted in Newe-Ya'ar Research Center experimental orchard in 2006. GF-677 serves as the main rootstock in Israeli commercial orchards. Three replicas of two trees per replica were planted along with 'Um ElFahem' as a reference cultivar in a multicultivar orchard. The orchard is grown under similar conditions to commercial practice. It was planted in clay grumusol (vertisol) soil at an elevation of $\approx 100 \mathrm{~m}$ above sea level, at lat. $32^{\circ} 42^{\prime} \mathrm{N}$, long. $35^{\circ} 11^{\prime} \mathrm{E}$. Yizre'el Valley is characterized by a Mediterranean subtropical climate, with an average annual rainfall of $\approx 580 \mathrm{~mm}$ concentrated from November through March. Mean diurnal minimum temperature in January is $6^{\circ} \mathrm{C}\left(43^{\circ} \mathrm{F}\right)$, and mean diurnal maximum temperature in July is $33{ }^{\circ} \mathrm{C}$ $\left(91{ }^{\circ} \mathrm{F}\right)$. The orchard was irrigated with $\approx 6000 \mathrm{~m}^{3} \cdot \mathrm{ha}^{-1}$ per year using a drip irrigation system. Each year, $\approx 250 \mathrm{~kg} \cdot \mathrm{ha}^{-1}$ nitrogen net content and $320 \mathrm{~kg} \cdot \mathrm{ha}^{-1}$ potassium net content were applied by a liquid fertilizer through the irrigation system.

Since planting, a detailed follow-up was done on tree and fruit characteristics, in comparison with other hybrids and to 'Um ElFahem'.

The data obtained indicate that 'Matan' is most suitable for commercial use. Since Feb. 2012, 'Matan' is registered under the terms of the Israeli Plant Breeders' Right Law 57331973 (registration no. 3150). 'Matan' was released to the Israeli growers during 2015, via a concessionary nursery, and there are no commercial orchards planted yet.

\section{Description}

The following description and measurements are of 4-year-old trees (unless otherwise indicated) as grown in an orchard in Yizre'el Valley, under the abovementioned agricultural practice. Color references, taken under conditions of full sunlight, are according to the Royal Horticultural Society (1986) color chart.

\section{Tree Characteristics}

Vigor and growth habit. 'Matan' trees are vigorous, upright, and moderately spreading. The main branches are round in shape and crown symmetrical in 30 to $60^{\circ}$ with respect to trunk axis. Bark color is grayed brown; its surface is semi-rough with gray elongated medium density lenticels. Tree height on the 4 th year is $\approx 4.5 \mathrm{~m}$ reaching up to $5.0 \mathrm{~m}$ for adult tree (on GF-677 under irrigated conditions). On average, branches grow $\approx 50$ to $60 \mathrm{~cm}$ per growing season. Vigor and growth rate are good and are not inferior to 'Um ElFahem' and 'Nonpareil'.

Foliage. Vegetative buds are conical, dark brown (RHS200B), covered with white hairs and adpressed toward the shoot. Leaf bud burst occurs at the end of February, after flowering. Foliage is dense and vital (Fig. 1). The narrow ovate leaf blade is rather big (length: $90-100 \mathrm{~mm}$; width: $20-30 \mathrm{~mm}$ ), and the length:width ratio is small. The leaf blade's base shape is right angle, and its apex is acute. The upper side is green (RHS147A), and its lower side is gray green (RHS137B). Margin incision is crenate, and venation is pinnate from central vein to the leaf edge. The main gray green (RHS137C) vein on the lower side is strongly prominent. The gray green petiole length is $19-20 \mathrm{~mm}$ and is 1-2 mm thick.

Pruning. The tree is trained on a relatively high trunk. On the first year after planting, trees are pruned to produce three to four main branches. From then on, light winter pruning is done for the removal of broken branches and inner branches, which interfere with light penetration of the canopy. 
Propagation. Dormant scions of 'Matan' are grafted easily on GF-677 rootstock. Other grafting methods were not tested, but there is no known reason that would prevent all grafting methods to be appropriate. Grafted trees showed uniformity of the cultivar characters.

Productivity. Fruit set occurs mainly on the distal part of the branch, and the nuts are arranged as a chain along the branches (Fig. 1). The nuts are well distributed throughout the tree on spurs. Under the conditions of Newe-Ya'ar, 'Matan' is highly productive and starts to crop 3 years after grafting. In Newe-Ya'ar, the average yield of first commercial kernel crop up to 2013 (fourth to eighth leaf) was $1429 \pm 33 \mathrm{~kg} \cdot \mathrm{ha}^{-1}$, whereas 'Um ElFahem' yielded $1409 \pm$ $65 \mathrm{~kg} \cdot \mathrm{ha}^{-1}$, at $5 \mathrm{~m}$ between the trees and $6 \mathrm{~m}$ between the rows. 'Matan' is a productive cultivar and produce equal yields as compared with 'Um ElFahem'. Any tendency to biennial bearing was not observed. 'Matan' was planted in two additional sites in Israel (details hereinafter in "Growing 'Matan' without pollenizers"). The yields in these orchards strengthen the advantage of 'Matan'.

Disease resistance. The climatic conditions in Newe-Ya'ar are favorable for leaf fungal diseases such as stone fruit rust [Tranzschelia discolor (Fuckel) Tranzschel \& Lit.], powdery mildew [Podosphaera tridactyla (Wallr.)], and Alternaria fruit spot [Alternaria alternata (Fr.:Fr.) Keissl.]. 'Matan' performs well under these conditions and displays an unusual green vital leaves, which remain unsheded until November. At this time of the year, the 'Um ElFahem' cultivar usually sheds most of its leaves. No special sensitivity of this cultivar to any disease or pest was detected.

\section{Blooming}

Flower. Flower buds are elliptical, dark brown (RHS200B), covered with white hair, and located on previous seasons shoot growth. The tips of petals within them are white pink (RHS56D), fading away with development. Flowers are born single or clustered (two or three per cluster). 'Matan' has a medium size $(2.8-3.5 \mathrm{~cm}$ in diameter) flower. The five broad elliptic and entire petals are smooth and medium undulated, $16-21 \mathrm{~mm}$ in length, and $10-15 \mathrm{~mm}$ in width. They have white (RHS155D) upper side and white with pink blush (RHS65D) lower side. The five broad elliptic, rounded apex, and entire sepals are $3-4 \mathrm{~mm}$ in length and width. Their outer side is grayish green (RHS138A-B) with strong anthocyanin coloration. Their inner side is green (RHS145B) sometimes with medium anthocyanin coloration and at base dark orange (RHS28B).

The numerous stamens have white (RHS155A) with purple (RHS183D) filaments and anthocyanin coloration, 4-7 mm in length. The minuscule anthers hold yellow (RHS5B) pollen. The pistil is very small and yellowish green (RHS149C). The stigma is placed at level or slightly above the anthers. The style is yellowish green (RHS149C) with many white hairs, $9-11 \mathrm{~mm}$ in length.

Flowering is abundant and the flowers have fragrance.

Time of bloom. 'Matan' is a midseason flowering cultivar compared with early flowering 'Um ElFahem' and late flowering 'Lauranne'. 'Um ElFahem' flowers in Newe-Ya'ar during February, and 'Lauranne' flowers during March. 'Matan' flowers from mid-February to the mid of the 2nd week of March.

Self-compatibility and pollination. 'Matan' is self-compatible and contains the $S f$ allele. Its second $S$ allele was not determined, supposedly $S 6$ or $S 7$ (donated by the 'Um ElFahem' parent). In addition to PCR analysis of leaves for the presence of the $S f$ allele, self-compatibility was reconfirmed by selfpollination in the field. This was done by hand pollinating castrated flowers and by bagging flower buds (autogamy). The results indicated bearing capacity of $38.0 \%$ to 42.7\% (in 2004 and 2005, respectively).

Since 'Matan' blooming time is later than that of 'Um ElFahem' and meets only the edge of the latter blooming period, it is not an efficient pollenizer for ' $U m$ ElFahem', although it is potentially capable to pollinate any almond cultivar including 'Um ElFahem'.

Chilling requirements of 'Matan' have not been determined. It was observed that less than 100 chilling hours (below $7{ }^{\circ} \mathrm{C}$ ) are sufficient for budbreak, good foliage cover, and blooming. It is considered as a cultivar with a low chilling demand.

\section{Fruit Characteristics}

Almond and kernel traits. 'Matan' has a large elongated nut. The nut shell is beige (RHS164C), semihard, intermediately pored, and completely sealed (Fig. 2). The nut multiannual average weight is $2.82 \pm 0.05 \mathrm{~g}$ (as compared with $1.59 \pm 0.06 \mathrm{~g}$ for 'Nonpareil' and 2.60 $\pm 0.04 \mathrm{~g}$ for 'Um ElFahem').

The kernel is ovate and large and its seedcoat surface tends to be slightly wrinkled. Nevertheless, 'Matan' has an attractive kernel. It has a brown red (RHS164A) seedcoat (Fig. 2). Its length is $2.82 \pm 0.05 \mathrm{~cm}$, its width is $1.55 \pm 0.03 \mathrm{~cm}$, its thickness is $0.79 \pm$ $0.02 \mathrm{~cm}$, and its weight is $1.48 \pm 0.03 \mathrm{~g}$ (as compared with $1.03 \pm 0.03 \mathrm{~g}$ for 'Nonpareil' and $1.47 \pm 0.04 \mathrm{~g}$ for 'Um ElFahem'). The kernel average percentage of the whole nut is $47.1 \%$. The kernel is sweet without any bitterness and was ranked higher than 'Um ElFahem' in taste examinations among evaluating panel. Mature 'Matan' produce less than $1 \%$ double kernels.

Harvest maturity. 'Matan' is ready for harvest at the beginning of August. In Newe Ya'ar, it is picked from $\approx 1$ Aug. to 15 Aug. The hull can easily be removed. It is readily picked by an almond shaker, with high efficiency, leaving a small quantity of almonds on the tree. However, it is not immediately dropping and can remain on the tree

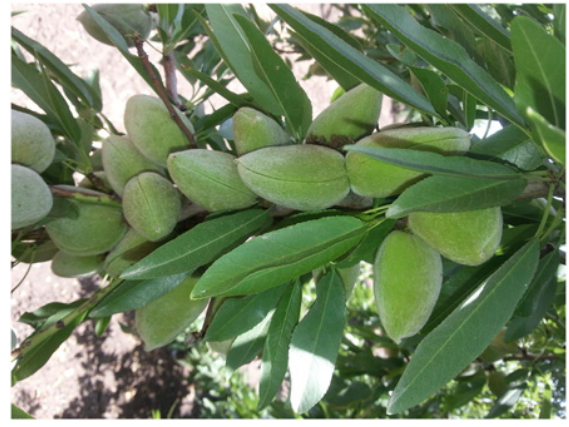

Fig. 1. 'Matan' branch: leaves and green nuts (photo taken in June at Newe Ya'ar Research Station).

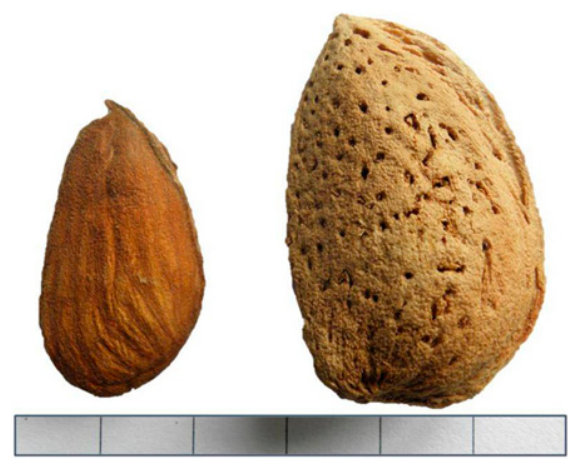

Fig. 2. Nut and kernel of 'Matan' almond. Each black/white square is equivalent to $1 \mathrm{~cm}$.

sometime until harvested. 'Um ElFahem', the main commercial cultivar in Israel, matures at Newe-Ya'ar in the end of July and 'Lauranne' 2-3 weeks later.

\section{Growing 'Matan' Without Pollenizers}

Self-compatible almond cultivars have a considerable advantage over commonly grown self-incompatible cultivars. Such cultivars can be grown in monocultivar orchards, without the necessity for pollenizers. Hence, it is easier to manage the orchards and the crop is homogenous. Selfcompatibility significantly reduce the dependence of yield on climatic conditions, which affect the time of flowering, the synchronization of flowering period between pollenizer and cultivar, and the activity of bees. This is especially important in Israel, where the almond commercial cultivars bloom during the cold rainy season. A selfcompatible cultivar will set fruit even in the absence of pollinating vectors, especially when the stigma is placed beneath or at the level of the anthers. It was found that most of the self-compatible Apulian almonds can be grown in a solid block, and pollinating insects contribute to efficient pollination (Godini et al., 1992). Therefore, such cultivars can improve orchard management and profitability. For examining 'Matan' performance in a block without pollenizers, a semicommercial test was established in 2009 in three different geographical locations: Newe Ya'ar 


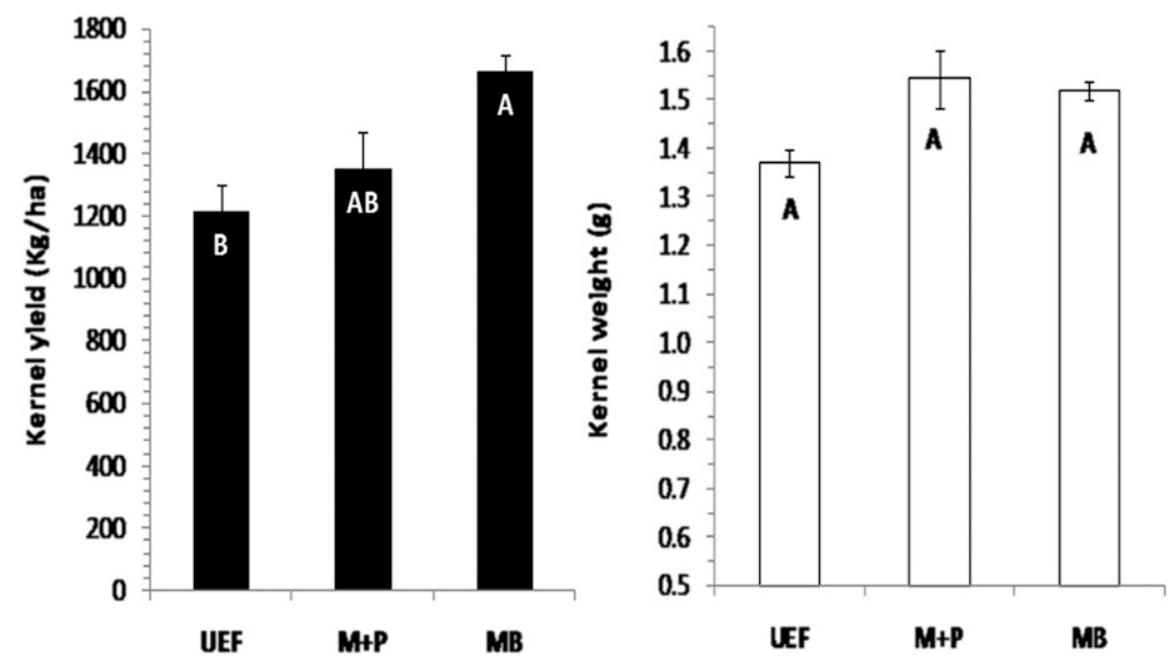

Fig. 3. Average kernel yield (right) and weight (left) of 'Matan' almond grown in block (MB) and with pollenizers (M+P) as compared with 'Um ElFahem' (UEF) during 2012 to 2014 in three geographical regions in Israel. The data reflect the averages of all three plots. The orchards were planted in 2009. Different letters indicate significantly different values.

Research Center, Magal, and Kfar Haruv. In the experimental plot, three different treatments were tested: 1) 'Matan' grown in a block of five rows without pollenizers, 2) two rows of 'Matan' grown with pollenizers ('Kochba' and 'Kochav'), and 3) two rows of ' $U m$ ElFahem' grown with its pollenizers ('Gilad' and 'Fergil') as reference. Planting distances are $6 \mathrm{~m}$ between the trees and $7 \mathrm{~m}$ between the rows. More than 10 trees were planted in each row. Statistics were based on the averages of the different plots (Newe Ya'ar Research Center, Magal, and Kfar Haruv) as three repeats. The average yield from 2012 to 2014 demonstrated that 'Matan' can be grown in a block without pollenizers and its yield performance and nut quality (Bar-Ya'akov et al., 2014) is equal or slightly exceeds that of 'Matan' with pollenizers. The results supported the above given data regarding its performance relative to 'Um ElFahem' (Fig. 3).

\section{Availability}

'Matan' is registered under the terms of the Israeli Plant Breeders' Right Law 57331973, registration no. 3150 from 14 Feb. 2012. The Agricultural Research Organization (ARO) is the owner of this cultivar. It was released for commercial use in Israel, by a concessionary nursery. 'Matan' is registered in the United States as US PP22,458 P3 from 17 Jan. 2012.

Nonindexed budwood is available pending concessions and a special contract through 'Kidum' R\&D Applications and Technology Transfer Unit of the ARO (http://www.agri. gov.i1/en/pages/1320.aspx).

\section{Literature Cited}

Barak, D. and S. Adawi. 1971. New almond cultivars from local seedlings selection. HaSadeh 51:1309-1311 (in Hebrew).

Bar-Ya'akov, I., K. Hatib, and D. Holland. 2014 Pollen source does not affect almond kernel size. Alon Hanotea 68:12-16 (in Hebrew).

Birger, R. 2000. Almond culture in Israel. Alon HaNotea 54:88-89 (in Hebrew).

Godini, A., L. de Palma, and M. Palasciano. 1992. Role of self-pollination and reciprocal stigma/ anthers position on fruit set of eight selfcompatible almonds. HortScience 27:887889.

Holland, D., R. Assaf, I. Bar-Ya'akov, K. Hatib, R. Birger, and A. Lin. 2003. New almond cultivars trials. Alon HaNotea 57:229-231 (in Hebrew).

Holland, D., I. Bar-Yaakov, T. Trainin, and K. Hatib. 2006. Old deciduous fruit trees of the Rosaceae in Israel and their utilization in modern agriculture and breeding. Isr. J. Plant Sci. 54:169-177.

Kester, D.E. 1995. Register of new fruit and nut varieties, Brooks and Olmo list 37, almond. HortScience 30:1135.

López, M., J.M. Alonso, P. Martinez-Gomez, R. Socias i Company, T.M. Gradziel, and I. Battle. 2001. Biological and molecular assessment of self-incompatibility in almond. FAO-CIHEAM, Nucis Nwsl. 10:8-11.

Royal Horticultural Society. 1986. R.H.S. color chart. Royal Horticultural Society, London; Flower Council of Holland, Leiden. 